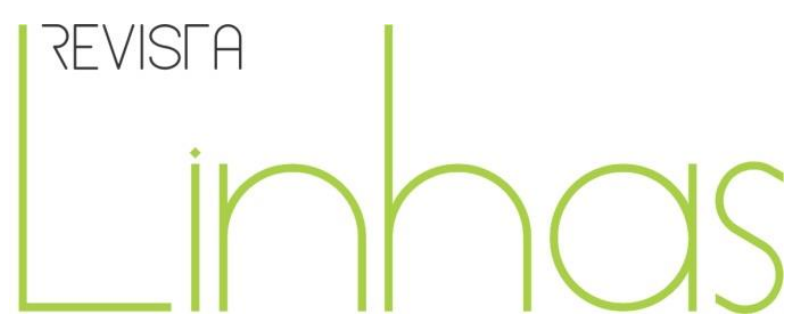

\title{
Resenha do livro "As histórias de vida: da invenção de si ao projeto de formação"
}

DELORY-MOMBERGER, Christine. As histórias de vida: da invenção de si ao projeto de formação. Tradução: Albino Pozzer. Natal: EDUFRN; Porto Alegre: EDIPUCRS; Brasília: EDUNEB. 2014. 362p. (Coleção Pesquisa (auto)biográfica $\infty$ Educação: Clássicos das Histórias de Vida).

\section{Ana Paula de Souza Kinchescki}

Mestre em Educação pela Universidade do Estado de Santa Catarina - UDESC - Brasil anapaulakin@gmail.com

\section{Luiza Pinheiro Ferber}

Mestre em Educação pela Universidade do Estado de Santa Catarina - UDESC - Brasil luizaferber@gmail.com

\section{Para citar esta resenha:}

KINCHESCKI, Ana Paula de Souza; FERBER, Luiza Pinheiro. Resenha do livro “As histórias de vida: da invenção de si ao projeto de formação”. Revista Linhas. Florianópolis, v. 16, n. 32, p. 412 - 417, set./dez. 2015. 
Os investimentos em torno do método de pesquisa (auto)biográfico têm conquistado espaço no cenário internacional. Como exemplo de iniciativas que têm como objetivo ampliar as discussões acerca dessa temática, pode-se citar as seis edições do Congresso Internacional de Pesquisa (Auto)biográfica - CIPA, que vem sendo organizado desde o ano de 2004.

$\mathrm{Na}$ terceira edição do referido Congresso, realizada no ano de 2008, foram apresentadas ao público coleções relacionadas ao tema e que tinham como objetivo demonstrar resultados da cooperação internacional, particularmente entre pesquisadores franceses e brasileiros. São elas: Collection (Auto) biographie et Education, coordenada por Christine Delory-Momberger, Maria da Conceição Passeggi e Elizeu Clementino de Souza, e Coleção Pesquisa (Auto)Biográfica e Educação, sob coordenação de Maria da Conceição Passeggi, Elizeu Clementino de Souza e Christine DeloryMomberger'.

O livro intitulado "As histórias de vida: da invenção de si ao projeto de formação", objeto desta resenha, é mais um resultado de ações com vistas a aprofundar reflexões relacionadas a esta temática e está contemplado na série Pesquisa (auto)biográfica $\infty$ Educação: Clássicos das Histórias de Vida. Esta série tem como objetivo dar ênfase a uma perspectiva intercultural, considerando diferentes formatos de textos que possibilitam distintos questionamentos e perspectivas, colaborando com as análises desenvolvidas em pesquisas que se apoiam em uma metodologia (auto)biográfica. Entre as obras presentes nessa coleção estão algumas re-editadas e outras mais conhecidas do grande público como "O método (auto)biográfico", organizado por António Nóvoa e Mathias Finger, “Narrativa de vida: a pesquisa e seus métodos", escrito por Daniel Bertaux, "Experiência e formação", de autoria de Marie-Christine Josso e "As histórias de vida”, produzido por Gaston Pineau e Jean-Louis Le Grand.

\footnotetext{
${ }^{1}$ Informações disponíveis no endereço eletrônico: <http://www.pucrs.br/eventos/cipa/?p=historico>. Acesso em: 25 set. 2015 .

2 Título original, em francês: “Les Histoires de Vie. De l'invention de soi au projet de formation”.
} 
A autora do livro resenhado, Christine Delory-Momberger ${ }^{3}$, é uma pesquisadora francesa, professora da Université Paris 8 e Paris 13, diretora adjunta desta instituição e coordenadora da pesquisa "Le sujet dans la Cité. Education, socialisation, biographisation" e suas produções (algumas já traduzidas e publicadas em língua portuguesa) têm contribuído para subsidiar reflexões tanto no Brasil quanto em outros países.

O livro "As histórias de vida", lançado pela editora Economic, foi publicado originalmente na França no ano de 2004. Traduzida para o português por Albino Pozzer ${ }^{4}$, a edição contém 362 páginas, sendo que as últimas onze são destinadas às referências bibliográficas utilizadas pela autora na confecção de seu trabalho. Estas referências por si só já se constituem em valiosas contribuições para aqueles que se ocupam do tema ou de seus correlatos.

Três editoras participaram da edição deste livro publicado no Brasil no ano de 2014: Edufrn (Editora da Universidade Federal do Rio Grande do Norte - UFRN); ediPUCRS (Editora da Pontificia Universidade Católica do Rio Grande do Sul - PUCRS) e Eduneb (Editora da Universidade Estadual de Brasília - UNEB).

O prefácio, denominado "Pensar 'o tolo projeto de retratar-se': da hermenêutica à ética", escrito por Michel Fabre ${ }^{5}$, dá início à produção, que segue com uma introdução e divide-se em duas partes principais, a primeira intitulada Práticas e invenção de si, subdividida em sete capítulos; e a segunda, A história de vida na encruzilhada das ciências humanas, com quatro capítulos, seguidos da conclusão e das referências bibliográficas.

De acordo com Fabre (2014), o livro escrito por Christine Delory-Momberger ajuda aqueles que têm interesse em pesquisar as histórias de vida, pois traz elementos que podem aprimorar a elaboração das questões que são desenvolvidas para analisar as “escritas de si”, inserindo-as “numa dupla história: a das práticas literárias ou cotidianas da escritura de si e das ciências humanas que tomam as primeiras por objeto" (FABRE, 2014, p. 22).

\footnotetext{
${ }^{3}$ Informações disponíveis no endereço eletrônico: <http://www.phanie.org/index.php/delory>. Acesso em: 23 set. 2015.

${ }^{4}$ Professor Adjunto da Pontifícia Universidade Católica do Rio Grande do Sul (PUCRS).

${ }^{5}$ Professor da Universidade de Nantes - Centro de Pesquisa em Educação de Nantes (CREN).
} 
A intenção da primeira parte é a de expor um trajeto que ajude a compreender as maneiras de como o Ocidente representou e se representou, perpassando a Antiguidade até o final do século XVIII, tratando sobre a questão da individualidade humana. A autora enfatiza suas análises principalmente na literatura por perceber a possibilidade de uma dupla reflexão: de um lado "ligado ao lugar da literatura na expressão e na formação da consciência de si de uma época; outro, à natureza do trabalho que a literatura realiza sobre o discurso de si" (DELORY-MOMBERGER, 2014, p. 185).

A partir daí, a autora começa uma "viagem" para tentar compreender as diversas maneiras encontradas pelo homem para escrever sobre sua história. Dessa forma, é discorrido no livro sobre as questões que envolvem o entendimento do cidadão como um homem em praça pública, ou, em outros termos, como sua imagem e sua posição na sociedade coincidem com a forma com que ele se autoidentifica, tendo a coletividade um papel essencial para esse sentimento.

Ainda ao tratar sobre as práticas e invenção de si, Christine Delory-Momberger busca problematizar períodos históricos nos quais as teografias e hagiografias estão presentes para a construção do reconhecimento da interioridade e como essas representações vão sendo modificadas ao passo em que o sentimento do "privado" é construído. Ainda sobre a questão do privado, na época Renascentista o ser humano começa a se "aventurar" na "reivindicação do valor e da iniciativa individuais face às forças coletivas ou institucionais" (DELORY-MOMBERGER, 2014, p. 92 ).

O texto avança refletindo sobre como as visões de individualidade e as escritas de si modificam-se de acordo com a época e o contexto. Os escritos relacionados ao homem da corte dão base para refletir como, por exemplo, a escrita de si pode ser influenciada e se confundir com os personagens que faziam parte da Corte. Além disso, traz elementos que demonstram como a formação da individualidade pode ser pensada a partir de situações feitas pelos iluministas e pela sociedade burguesa, que traz outras formas de organizar o mundo e a vida. Para a autora 
Nossas práticas de narrativas de si entram na História e tornam-se compreensíveis só através dela e em comparação com as formas passadas; contudo, não podemos situá-las num eixo temporal linear, num eixo de progresso do qual elas marcariam um acabamento qualquer, nem, aliás, numa dialética que faria de cada figura ao mesmo tempo a superação e a realização das precedentes. (DELORY-MOMBERGER, 2014, p. 24-25)

A segunda parte do livro, intitulada "A História de vida na encruzilhada das Ciências Humanas", trata de algumas perspectivas que abordam a construção da história de vida a partir de uma visão mais sociológica, com a intenção de pensar o ser humano em formação, levando em conta suas questões individuais, sem desconsiderar as formas de interação com os outros.

Conforme os estudos da autora, é possível perceber distintas correntes epistemológicas ao longo da história, como, por exemplo, embates em torno de concepções mais racionalistas ou positivistas. Além disso, seu texto possibilita compreender a tomada de consciência que o homem começa a ter de si mesmo e da formação consigo e com a sociedade, porém, para que isto aconteça, ele precisou passar por rupturas e transformações em sua essência. Nas palavras de Delory-Momberger (2014, p. 349) "é no pretendido distanciamento do sujeito em relação a si mesmo que pode situar-se este projeto de uma história a ser feita e realizar-se a dimensão emancipadora da educação, quando ela visa encarregar-se, por si mesma, da pessoa".

Destaca-se, portanto, a relevância desta produção tendo em vista o investimento da autora em ler, pesquisar e escrever de forma a pensar nas histórias de vida, seu processo de construção, mudanças e análises ao longo do tempo, por meio de relatos orais, diários, escritas escolares, literatura, biografias, entre outros objetos e fontes que possam ajudar na pesquisa do humano como um ser. 


\section{Referências}

DELORY-MOMBERGER, Christine. As histórias de vida: Da invenção de si ao projeto de formação. Tradução: Albino Pozzer. Natal: EDUFRN; Porto Alegre: EDIPUCRS; Brasília: EDUNEB. 2014. 362p. (Coleção Pesquisa (auto)biográfica o Educação: Clássicos das Histórias de Vida).

FABRE, Michel. Prefácio - Pensar "o tolo projeto de retratar-se": da hermenêutica à ética. In: DELORY-MOMBERGER, Christine. As histórias de vida: Da invenção de si ao projeto de formação. Tradução: Albino Pozzer. Natal: EDUFRN; Porto Alegre: EDIPUCRS; Brasília: EDUNEB. 2014. (Coleção Pesquisa (auto)biográfica $\infty$ Educação: Clássicos das Histórias de Vida). p. 21-29.

PHANIE, Centre de L'ethnologie, La sociologie ET l'antropologie. Christine DeloryMomberger. Disponível em: <http://www.phanie.org/index.php/delory>. Acesso em: 23 set. 2015 .

V CIPA, Congresso Internacional de Pesquisa(Auto)biográfica. Histórico. Rio Grande do Sul, PUCRS, 2012. Disponível em: <http://www.pucrs.br/eventos/cipa/?p=historico>. Acesso em: 25 set. 2015 .

Universidade do Estado de Santa Catarina - UDESC Programa de Pós-Graduação em Educação - PPGE 